\title{
Producing Useful Chemicals Using a Nuclear Reactor
}

\author{
Arran George Plant, Dr Vesna Najdanovic-Visak*, Professor Malcolm J. Joyce, Dr. Luka Snoj and Anže Jazbec \\ Engineering Department, Lancaster University \\ *v.najdanovic@lancaster.ac.uk
}

In this paper, the irradiation of glycerol and ethylene glycol by either mixed (neutron- $\gamma$ ) or $\gamma$-only $(\nu)$ fields at the TRIGA reactor of the Jožef Stefan Institute is described. This is highly relevant to future applications of fission reactor systems to produce useful feedstock derivatives from organic waste, beyond the production of heat and power.

Samples of glycerol and ethyl glycol have been exposed to neutron-gamma radiation with fast neutron fluxes ranging from $7.7 \times 10^{10}$ to $3 \times 10^{12} \mathrm{~cm}^{-2} \mathrm{~s}^{-1}$ and gamma-only irradiation at maximum dose-rates of 492 and $10 \mathrm{kGy} \mathrm{hr}^{-1}$, respectively. A study of the dependence of product yield versus absorbed dose has been conducted, for total dose ranges of 1 to $100 \mathrm{kGy}$. The products of these exposures have been identified through Gas Chromatography - Mass Spectrometry (GC-MS) techniques.

Analysis comparing neutron-gamma irradiated samples of ethylene glycol and glycerol with gamma-irradiated samples shows no detectable qualitative difference between either irradiation type. Although, additional radiolysis products were detected when compared with available literature; ethyl acetate from ethylene glycol and solketal from glycerol. Quantitatively, neutron-gamma irradiation seems to be less effective at producing acetaldehyde from ethylene glycol, compared with gamma-only which can be explained through neutron moderation and consequent heating effects due to the borosilicate vials.

Keywords - Chemical analysis, Chemical engineering, Neutron radiation effects, Organic chemicals, Radiolysis

\section{INTRODUCTION}

$\mathrm{R}$ ADIATION chemistry concerns the study of chemical processes within materials that are initiated by ionizing radiation, these processes can also be referred to as radiolysis. Many applications using highly ionizing radiation have been realised throughout history and implemented in the current commercial world, such examples include polymer synthesis, sterilization and cleaning of flue gases. [1]

In literature, there have a number of examples in that types of radiation have been used to synthesise organic chemicals through catalytic processes. [2] Such an example is the

This Work was supported by the EPSRC.

Arran George Plant (email:a.plant@lancaster.ac.uk), Dr Vesna NajdanovicVisak (email:v.najdanovic@lancaster.ac.uk) and Professor Malcolm J. Joyce (email:m.joyce@lancaster.ac.uk) are with Lancaster University, LA1 0PF UK production of ethyl bromide which proved to be successful for a number of years. [3] This process which was implemented by the Dow Institute in 1963 used a cobalt-60 source which emitted prompt-gamma rays with an activity of $\approx 10^{15} \mathrm{~Bq}$. This large scale process managed to output approximately 500 $\mathrm{kt} \cdot \mathrm{year}^{-1}$ with a radiochemical yield, $\mathrm{G}$ of $\approx 10^{5}$ per $100 \mathrm{eV}$ and fulfilled Dow's entire production of ethyl bromide to the common market.

Most radiolysis literature has focused on the use of electron, heavy ion beams and gamma rays for their interactions with materials. There has been very little published for the use of neutrons or 'pile' irradiation for the radiochemical synthesis of commodity chemicals. [4] A neutron-emitting device such as a commercial nuclear fission reactor would serve as a source which would be suitably powerful enough to initiate chemical transformations in a timely manner.

A recent economic study concluded that such an integrated chemical-nuclear process could be economically feasible within a commercial nuclear reactor's design, with relatively little additional capital costs associated with the inclusion of radiochemical process. $[5,6]$

Currently, there is still a heavy reliance on the petrochemical industry for the supply of commodity chemicals; therefore research into alternative, chemical processes that utilize waste natural feedstocks is vital to create a more sustainable future.

For this experimental radiolysis research, Glycerol can be identified as a potential, abundant renewable feedstock for radiation processing due to its large opportunity for valorisation.[7] Due to this low price, it has mainly been used for low-energy applications such as animal feed or incineration fuels. Due to research within the last decade, a number of thermochemical routes to upgrade the versatility of glycerol to value-added products have been explored.

However, there have only been a few attempts to explore the use of highly ionizing radiation to transform and valorise glycerol into a useful commodity. Radiation research has been limited to explore the effects of gamma and ion beams. [8-10] There has been no available literature for the interactions of neutrons on glycerol or many other organic compounds, therefore the use of neutron or 'pile' irradiation has potentially been overlooked as a source of intense energy to catalyse reactions.

In this paper, the use of neutron and gamma radiation for the

Dr Luka Snoj (luka.snoj@ijs.si) and Anže Jazbec (anze.jazbec@ijs.si) are with the Jozef Stefan Institute, Jamova 39, 1000 Ljubljana, Slovenia 
processing of glycerol and ethylene glycol to more useful, valuable products is explored. Ethylene glycol was chosen as another feedstock due to its similar chemical structure to glycerol; it also offered more favourable physical properties such as lower viscosity and boiling point which is preferable for sample preparation for analysis. A comparative study between existing literature of gamma studies and this new experimental work is conducted, together with the description of the methods used to irradiate and chemically analyse samples of ethylene glycol and glycerol.

\section{EXPERIMENTAL METHODS}

\section{A. Irradiation Methods}

Samples of ethylene glycol and glycerol were irradiated in a MKII TRIGA reactor located at the Jožef Stefan Institute (JSI). This light water, pool-type reactor can operate at a maximum power of $250 \mathrm{~kW}$, giving neutron fluxes as high as $10^{13} \mathrm{~cm}^{-2} \mathrm{~s}^{-1}$. [11] The inner reactor core itself, where the largest neutron fluences can be utilized has five different radiation channels; most notably is Triangular Irradiation channel (TriC) in which samples as large $4 \mathrm{~cm}$ diameter can be lowered down into the reactor's core. Compared with the other channels of this comparable size, this channel offers a higher percentage of fast neutrons flux $(\approx 33 \%)$ and is utilized for these irradiations.

For a comparative study between irradiation types, organic samples were irradiated in two different reactor modes, current and shutdown mode. The 'current mode' allows samples to be irradiated with a combination of neutrons, delayed $\gamma$ and prompt $\gamma$ rays. In this mode, the majority of absorbed dose deposited in the organic material would be contributed by neutrons. When the reactor is in its 'shut down' mode, the samples are irradiated with only delayed gamma waves with the dose rates dependent on the exponential decay of the activated fuel after reactor operations.

For a radiochemical product comparison between the two types of irradiations of $n+\gamma$ (neutrons and gamma) and $\gamma$-only (gamma-only), samples of ethylene glycol and glycerol were irradiated with $50 \mathrm{kGy}$ of absorbed dose in either field.

For a quantitative radiochemical comparison, samples were irradiated with doses of 1, 10, 20, 50 and $100 \mathrm{kGy}$ for each reactor mode/irradiation type respectively.

The samples of ethylene glycol and glycerol were crimpsealed within $20 \mathrm{ml}$ round-bottomed GC-MS (Gas Chromatography-Mass Spectrometry) headspace vials with a mostly inert nitrogen atmosphere. In existing radiolysis literature, [8-10] organic volatile losses were problematic when preparing samples for analysis.

Once irradiated, the sample vials were stored in a $-18^{\circ} \mathrm{C}$ freezer until transport back to Lancaster University for chemical analysis. The samples were then stored in a $4^{\circ} \mathrm{C}$ refrigerator until time for analysis.

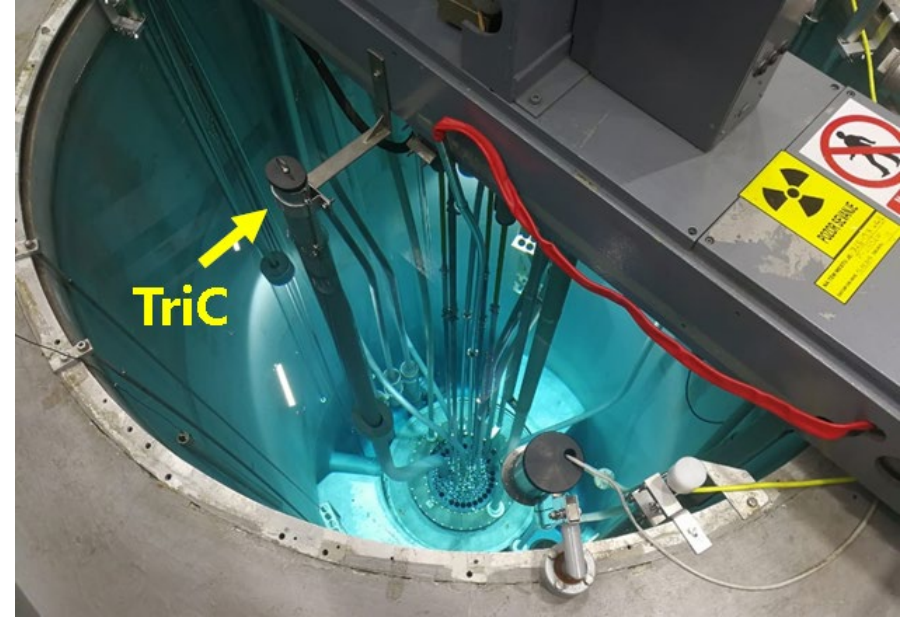

Fig. 1. Top View of the JSI TRIGA Reactor indicating the access port for the Triangular Irrational Channel.

\section{B. Chemical Analysis Methods}

To determine the difference in radiochemical products between $n+\gamma$ and $\gamma$-only irradiation qualitatively, samples were analysed using gas chromatography-mass spectrometry (GC$\mathrm{MS}$ ) to identify the unknown products. The GC system that was used was a Shimadzu TQ8040 GC-MS, equipped with an AOC6000 autosampler for repeatable, reproducible injections. Each separated peak response being referenced against the NIST 11 Standard Reference database for MS fragment patterns.

The GC separations of the organic samples were performed using a fused silica Zebron 624-Plus capillary column; with a length of $30 \mathrm{~m} \times 0.25 \mathrm{~mm}$ i.d. and a film thickness of $1.4 \mu \mathrm{m}$. To protect the stationary phase of the column, a $10 \mathrm{~m}$ fusedsilica column guard was installed at the beginning a connected to the analytical column. The oven temperature was programmed as follows; $40{ }^{\circ} \mathrm{C}$ (10mins); Ramp of $25^{\circ} \mathrm{Cmin}^{-1}$ to hold at $300{ }^{\circ} \mathrm{C}$ (2.6 min). Split injections of a volume of $1 \mu \mathrm{l}$, with a split ratio of 20:1 with a constant column flow of 1.71 $\mathrm{ml} \cdot \mathrm{min}^{-1}$ during a run. The carrier gas type used was Helium with a purity of $99.999 \%$. The injection port temperature was set at $300{ }^{\circ} \mathrm{C}$, the MS ion source temperature at $250{ }^{\circ} \mathrm{C}$ and the $\mathrm{GC}$ to MS interface at $300{ }^{\circ} \mathrm{C}$. A fragment mass range of $\mathrm{m} / \mathrm{z}$ 30-300 was measured in scan mode with a scan rate of 1000 scans per second.

\section{RESULTS AND DISCUSSION}

\section{A. Qualitative Comparison \& Radiolysis Products}

Comparing the radiolysis products between the two different irradiation types, there did not seem to be any unique products formed from the $n+\gamma$ irradiation type compared with the $\psi$-only. 
The following tables list the radiolysis products for both modes of irradiation;

TABLE I

$\mathrm{N}+\Gamma \&$ \&-ONLY RADIOLYSIS PRODUCTS OF ETHYLENE GLYCOL

\begin{tabular}{|c|c|c|c|}
\hline $\begin{array}{c}\text { Peak } \\
\text { Numbe } \\
\text { r }\end{array}$ & $\begin{array}{c}\text { NIST } 11 \text { Library Given } \\
\text { Compound/ Radiolysis } \\
\text { Product }\end{array}$ & $\begin{array}{c}\% \\
\text { Similarity } \\
\text { Match }\end{array}$ & $\begin{array}{c}\text { Prior } \\
\text { Literature? }[10]\end{array}$ \\
\hline 1 & Carbon Dioxide & 97 & $\bar{Y}$ \\
\hline 2 & Formaldehyde & 97 & $\mathrm{Y}$ \\
\hline 3 & Methanol & 97 & $\mathrm{Y}$ \\
\hline 4 & $\begin{array}{l}\text { Acetaldehyde } \\
\text { (Confirmed) }\end{array}$ & 98 & $\mathrm{Y}$ \\
\hline 5 & $\begin{array}{l}\text { Ethyl Acetate } \\
\text { (Confirmed) }\end{array}$ & 98 & $\begin{array}{l}\text { N.R. (Not } \\
\text { Reported) }\end{array}$ \\
\hline 6 to 12 & $\begin{array}{l}\text { Miscellaneous } \\
\text { Polymeric Structures }\end{array}$ & $<89$ & N.R. \\
\hline
\end{tabular}

TABLE 2

$\mathrm{N}+\Gamma \&$ $\&$-ONLY RADIOLYSIS PRODUCTS OF GLYCEROL

\begin{tabular}{clcc}
\hline \hline $\begin{array}{c}\text { Peak } \\
\text { rumbe }\end{array}$ & $\begin{array}{l}\text { NIST 11 Library Given } \\
\text { Compound/ Radiolysis } \\
\text { Product }\end{array}$ & $\begin{array}{c}\% \\
\text { Similarity } \\
\text { Match }\end{array}$ & $\begin{array}{c}\text { Prior } \\
\text { Literature? } \\
{[8,9]}\end{array}$ \\
\hline 1 & Carbon Dioxide & 94 & Y \\
2 & Methanol & 97 & Y \\
3 & Glycoaldehyde Dimer & 96 & Y \\
4 & Acetol (Confirmed) & 97 & Y \\
5 & Propylene Glycol & 91 & Y \\
6 & 1,2,3-Butanetriol & 84 & Y \\
7 & 2-(2-Methoxyethoxy) ethyl & 81 & N.R. \\
& acetate & & \\
8 & Solketal (Confirmed) & 97 & N.R \\
9 to 11 & Further Miscellaneous & $<89$ & N.R. \\
& Polymeric Structures & &
\end{tabular}

$\mathrm{Y}$ indicates a mention in literature, N.R. indicates not reported radiolysis compounds.

Radiolysis Products that have been confirmed using internal standards have been indicated.

As shown by the analysis, there are a number of products from both the radiolysis of ethylene glycol and glycerol which agree with the available reported literature.

Some of the unreported products which are listed have been matched to chemicals with a low similarity match $(<90 \%)$. It is thought that over time, the formation of larger, more complex polymeric chemicals have formed which cannot be referenced accurately against available fragmentation patterns. Such primary radiolysis products such as acetic acid and acetaldehyde can be highly reactive with other components within the mixture, allowing these higher-order products to form.

From ethylene glycol radiolysis, one previously unreported product that was detected was ethyl acetate, it is possible that it has been formed from the reaction between radiolysis-produced acetic acid and ethanol over time. Ethyl acetate is most commonly used as a solvent in a wide array of applications such as for cleaning electronics, coating formulations and pharmaceuticals.

From glycerol radiolysis, one notable product formed which is not listed in literature is solketal (isopropylidene glycerol). Solketal is a chemically protected form of glycerol which is commonly used as an intermediate in organic synthesis when attempting to selectively interact with a single hydroxyl functional group of glycerol. In this radiolysis research,
Solketal is thought to have been formed through secondary processes over time with reactive primary products, similarly for the polymeric products. As a useful product, Solketal can be utilized as a green solvent with interesting properties [12] When compared to Glycerol, Solketal has a greater potential to be used as a renewable, green solvent with a boiling point of 188 ${ }^{\circ} \mathrm{C}$, a viscosity of $11 \mathrm{cP}$ and is miscible in most organic solvents. Glycerol derivatives such as Solketal also have great potential to be used as fuel additives.

\section{B. Quantitative Comparison of Radiation Types}

For an initial comparison between the two irradiation types, the concentration of a primary radiolysis product, acetaldehyde from ethylene glycol has been plotted against the absorbed dose.
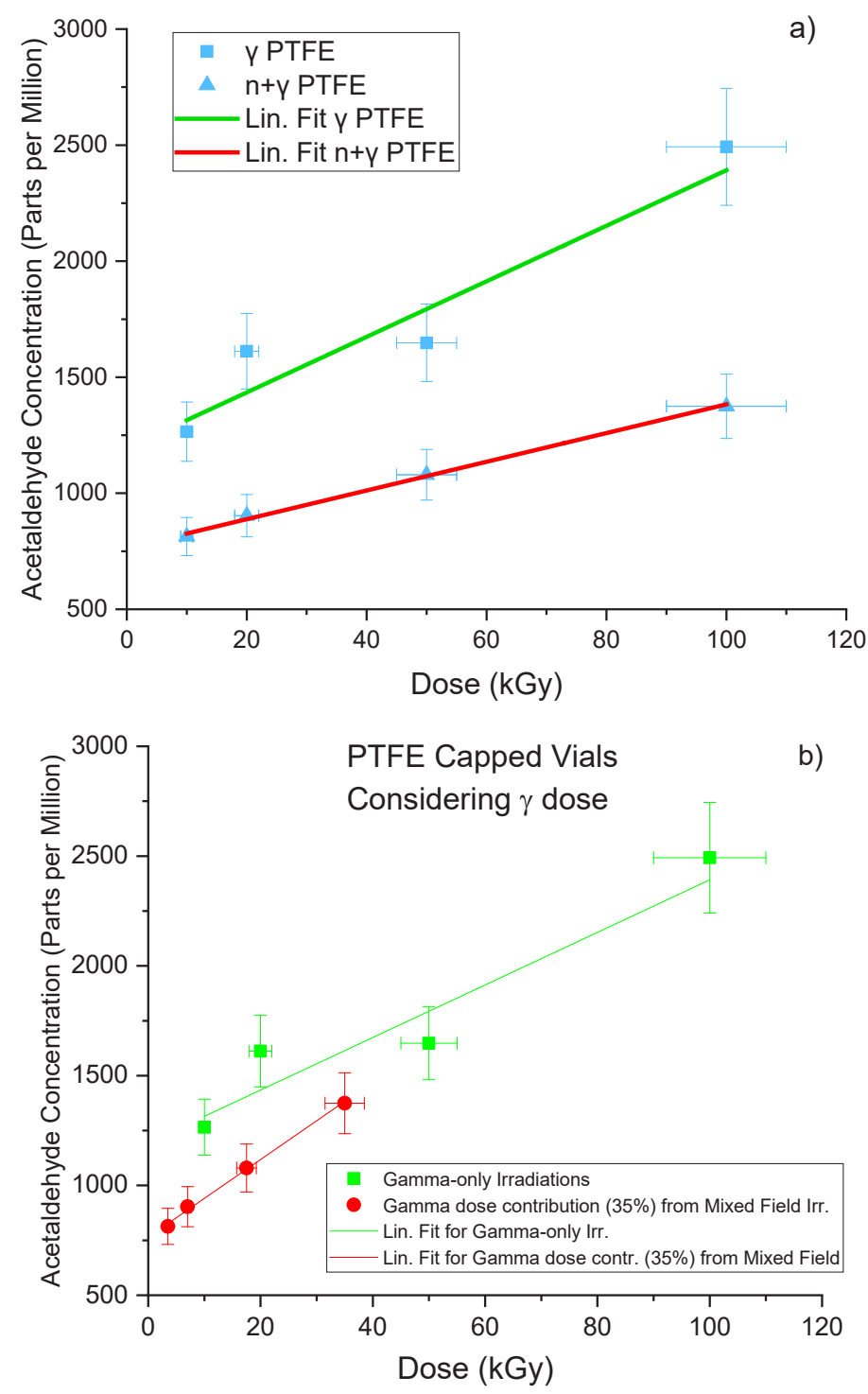

Fig. 2. Acetaldehyde concentration comparison between $n+\gamma$ (red) and $\gamma$-only (green) radiation modes for the radiolysis of ethylene glycol in PTFE vials; a) Direct Comparison b) Considering $\gamma$-dose only for $n+\gamma$

When comparing the irradiation types, there seems to be a greater concentration detected from the $\gamma$-only irradiated samples for both septa types. This goes against the 
unsupported comments in the literature that the two radiation types are similar in terms of their radiolysis effectiveness. [1]

However, when considering just the gamma dose contribution $(\approx 35 \%)$ from the mixed $n+\gamma$ field irradiations, Fig. $2 \mathrm{~b}$ can be generated.

From Fig. 2b, the two sets of data can be considered statistically similar in terms of their gamma-dose contribution. One explanation for the lower concentration observed is the boron content within the borosilicate vials themselves. The boron would absorb some of the absorbed dose intended for the organic samples. Boron-11 has a high cross-sectional area for thermal neutron $(<0.025 \mathrm{eV})$ capture, acting as a neutron moderator. Also, Boron-10 has a high neutron cross-sectional area across the entire neutron energy spectra range which is unlike most isotopes. [13]

The second factor that could lead to reduced yields is the slight temperature increase accompanied by the boron acting as a neutron moderator, heating the vials during irradiation. A slight temperature increase could have a couple of unintended effects. One could be an increase in the rate of volatile loss from the vial. The second could be the increase in the rate of diffusion of the initial radical species, increasing the chance of recombination and decreasing molecular yields. [14]

\section{REFERENCES}

[1] Woods, Robert J., and Alexei K. Pikaev. "Applied radiation chemistry: radiation processing." John Wiley \& Sons, 1993 pp. 37

[2] (IAEA), I.A.E.A. "Industrial uses of large radiation sources, vol.2. in Application of Large Radiation Sources in Industry" Vol II. . 1963. Austria.

[3] Harmer, D. E., et al. "The Dow ethyl bromide process: an industrial application of radiation chemistry." Industrial Uses of Large Radiation Sources. Proceedings of a Conference on the Application of Large Radiation Sources in Industry. Vol. II. 1963., pp. 205-230

[4] Collinson, E., and Albert J. Swallow. "The radiation chemistry of organic substances." Chemical Reviews 56.3, 1956 pp. 498, 506.

[5] McConnaughy, Thomas B., Matthew R. Shaner, and Eric W. McFarland. "A Techno-Economic Analysis of Chemical Processing with Ionizing Radiation." Chemical Engineering \& Technology 40.6 (2017): 1196-1202.

[6] Schmeda-Lopez, Diego, Thomas B. McConnaughy, and Eric W. McFarland. "Radiation enhanced chemical production: Improving the value proposition of nuclear power." Energy 162 (2018): 491-504.

[7] Ciriminna, Rosaria, et al. "Understanding the glycerol market." European Journal of Lipid Science and Technology 116.10 (2014): 1432-1439.

[8] Baugh, Peter J., et al. " $\gamma$-Radiolysis of N2O-saturated aqueous glycerol solutions: Product yields and free radical mechanism." Radiation Physics and Chemistry (1977) 20.3 (1982): 215-222

[9] Keough, T., et al. "Comparison of the stable products formed by fast atom bombardment and $\gamma$-irradiation of glycerol." Organic mass spectrometry 22.5 (1987): 241-247.

[10] Barker, S. A., J. S. Brimacombe, and E. D. M. Eades. "Action of gamma radiation on liquid ethylene glycol." Radiation research 22.2 (1964): 357-367.

[11] Snoj, Luka, Gašper Žerovnik, and Andrej Trkov. "Computational analysis of irradiation facilities at the JSI TRIGA reactor." Applied Radiation and Isotopes 70.3 (2012): 483-488.

[12] García, José I., Héctor García-Marín, and Elísabet Pires. "Glycerol based solvents: synthesis, properties and applications." Green Chemistry 16.3 (2014): 1007-1033.
[13] N. Soppera, M. Bossant, E. Dupont, "JANIS 4: An Improved Version of the NEA Java-based Nuclear Data Information System", Nuclear Data Sheets, Volume 120, June 2014, Pages 294-296.

[14] Donoclift, Thomas. "The Radiolytic Steady-State and Factors Controlling H2 Production.” Diss. University of Manchester, 2017. 